\title{
Abdominal and inguinal hernias in camel (Camelus dromedarius) in Saudi Arabia (Field Cases)
}

\author{
Ramadan, R.O and M. R. Abdin-Bey \\ College of Veterinary Medicine and Animal Resources, King Faisal University, \\ Alhasa, Saudi Arabia
}

\begin{abstract}
Ventral abdominal hernia (VAH) and inguinal hernias (IH) were encountered with higher frequencies in camels. The hernial swellings of VAH were situated on the sides of the body below the flank, near the costochondral junction up to the callosity. Females outnumbered males. The swelling occurred more on the left than the right side. The hernial contents were omentum, loop of intestines or part of the liver. One or more hernial ring and one or more separate swelling were found. The hernial swelling of inguinal hernia were found more in the left than in the right caudo-dorsal part of the udder. Its content was loop of intestines, the horn of the uterus together with its ovary. Inguinal hernia was said to lead to repeat breeding. Herniorrhaphy attained good results. During surgery, the contents were reduced and the ring encored with Dexon II -6 metric or Polyester 6 Metric or with an 18-G stainless steel wires. Prognosis was good.
\end{abstract}

Keywords: hernias, surgery, camel, Saudi Arabia.

\section{Introduction}

There is an increasing awareness that abdominal and inguinal hernias in animals may entrap a gravid uterine horn (Snow, 1956; Sobiraj 1994; Abdin-Bey and Ramadan, 2001). Abdominal hernias alter body conformation and distort the cosmetic appearance of the animal body. Hernias may lead to incarceration or strangulation of internal organs within the hernial sacs. Despite these facts, we are faced with paucity of information regarding hernias in camels (Purohit et al 1982;Ramadan, 1986; Ramadan, 1994).Ventral hernias may be of primary origin developing after blunt injury (Gahlot,2000) or it may arise secondary to caesarian operation following disruption of abdominal muscles during healing (Purohit et al. 1989; Bolbol and Ramadan 1992). The purpose of this study was to report abdominal and inguinal hernias in camels in Saudi Arabia.

\section{Materials and Methods}

During 1995-2000, 26 cases of ventral abdominal hernia (VAH) and inguinal hernias (IH) were diagnosed. Twenty-one animals had VAH (one of them occurred 7 months from the last cesarean operation). Their age, sex, and site of the hernia were listed in table.1. The remaining five she camels had inguinal hernias.

\section{Results}

Female generally outnumbered male $(5: 1)$ in this study. The mean age at the time of presentation was 3.5 years (range 218 years) for the female and 7 years for the male. The left side of the boy was affected more than the right side (1.5:1). Inguinal hernias were noted more in the left than the right side (4:1).

Ventral abdominal hernia

There were history of bite or other form of trauma in eighteen cases. The remaining two cases developed after evacuation of abscess from the region. One animal developed the hernia after cesarean operation. The hernial swelling occurred on one side of the body wall, ventral to the flank and up to the caudal edge of the callosity (Fig.1). The swelling varied from lemon size up to the child head. The ring was located towards the middle of the swelling and varied from $2 \mathrm{~cm}$ up to $20 \mathrm{~cm}$ in diameter. Two or more separate rings could be found in one swelling, thus being 


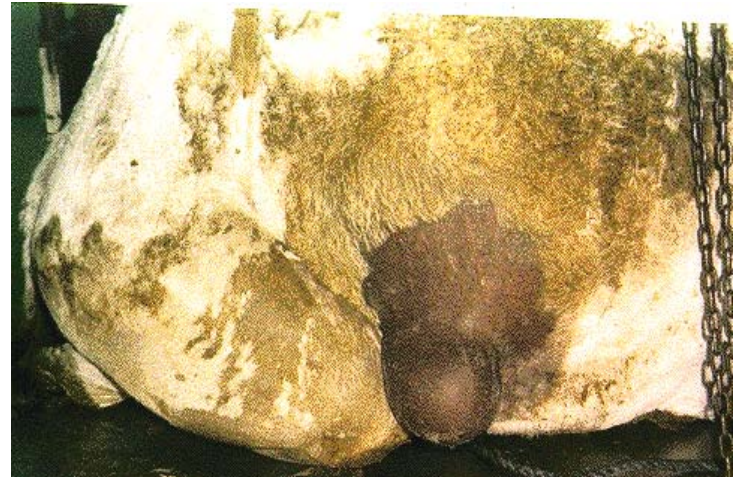

Fig. 1. A rounded hernial swelling ventral to the right flank

separated from each other by delicate fibers. Occasionally two different swellings were encountered, side by side; each swelling had its own hernial ring (Fig.2). The contents were mostly omentum, loop of intestines or a piece of liver.

It could be noted that the hernia that developed secondary to caesarian operation was characterized by subtle swelling and indurated scar formation.

Inguinal hernia

The age of the animals ranged from 3 to 10 years. All five animals were females. The swellings occurred mostly on the left thanon the right side (4:1). The hernial swelling was always unilateral, occurring above the mammary gland. In its early stage, the swelling was defuse but later on it attained an oval or round orange shape causing asymmetry of the inguinal region. This latter swelling was best noted with the

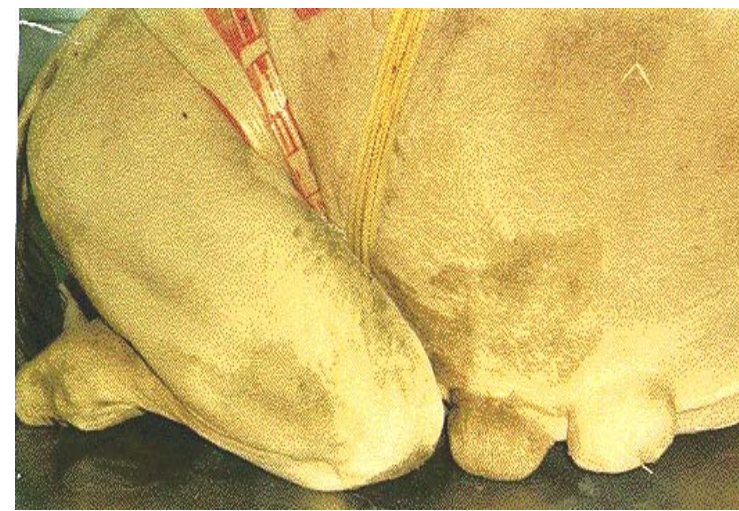

Fig. 2. Double hernial swelling on the right side of the body.

camel on the sitting position. Occasionally the swelling may attain a football size (Fig.3), compressing on the udder tissue. The external hernial ring could be felt with great difficulty (Fig.4). Rectal examination revealed wide internal inguinal opening and possible entrapment of the uterine horn and loops of intestines. The latter could be withdrawn through the rectum

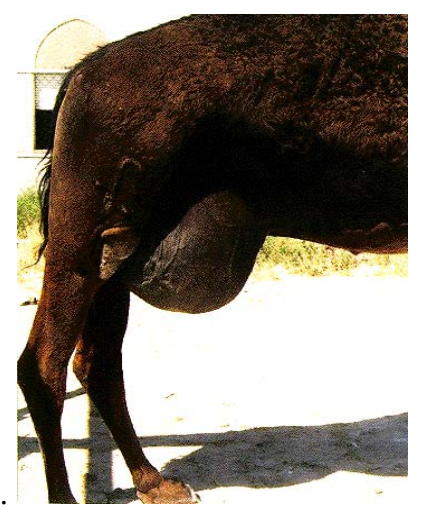

Fig. 3. Severe football size swelling due to inguinal hernia.

Table. 1. Site of abdominal hernia and age of affected ale and female camels

\begin{tabular}{ccccc}
\hline \multirow{2}{*}{ Particulars } & \multirow{2}{*}{ No. of Camels } & Age Range & \multicolumn{2}{c}{ Site } \\
\cline { 4 - 5 } Male & 4 & $4-10$ & Right & Left \\
Female & 17 & $2-18$ & 8 & 3 \\
\hline
\end{tabular}

Clinical signs 
Emir. J. Agric. Sci. 2001. (13) : 57-61

http://www.cfs.uaeu.ac.ae/research/ejas.html

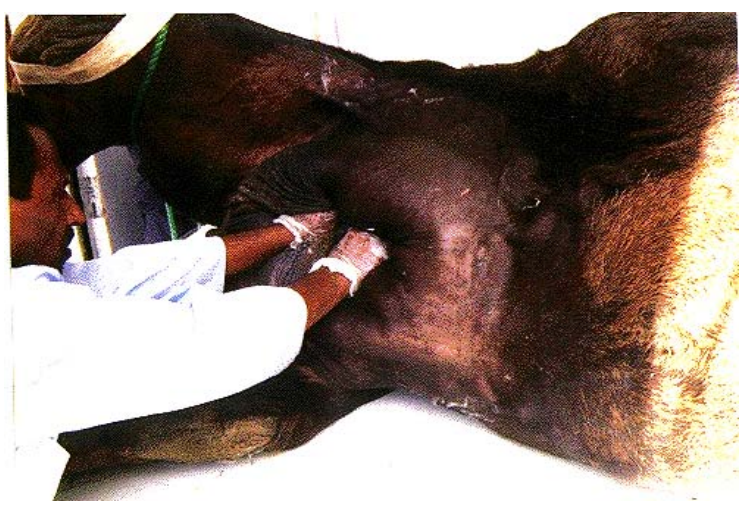

Fig. 4. Same animal in figure 3 to show the ring.

\section{Surgery}

\section{Preparation and anaesthesia}

The animal was fasted for two days. Water was allowed up to six hours before operation. Each animal was sedated with Xyalzine (Seton 2\%, Barcelona Spain) at the dose of $0.2 \mathrm{mg} / \mathrm{Kg}$ Bwt given intravenously. This was followed by an intravenous injection of ketamine hydrochloride (Ketamidore, Richter Pharma AG, Wels Austria) at the dose of $1 \mathrm{mg} / \mathrm{kg}$. B wt. The anaesthesia was maintained by repeated injection of half dose of the xylazine and ketamine hydrochloride solution given every 20-30 minutes.

\section{Surgical Technique}

For ventral abdominal hernia the animal was cast on one side with the operative site uppermost. An elliptical incision was run around the swelling. The skin was discarded after being dissected from the subcutaneous tissues (Fig.5). The hernial ring was identified, and the hernia content was pushed into the abdominal cavity. Alternatively, the inner hernial sac was opened so as to break any adhesion and facilitate suturing. The hernial ring was coaptated with double strand of Dexon II 5 metric in a figure of eight pattern. This treatment was valid when the ring was from 2-7 $\mathrm{cm}$ in diameter (Fig.6). When the ring was large, polyester (Polydeck No 6 metric or
18-G stainless steel wire was used to close the hernial ring in a figure of eight, mattress or Myo-mattress suture pattern. Another continuos or continuous lock stitch follows. The subcutaneous fascia and skin were closed routinely. Prophylactic antibiotic was given for 5 days.

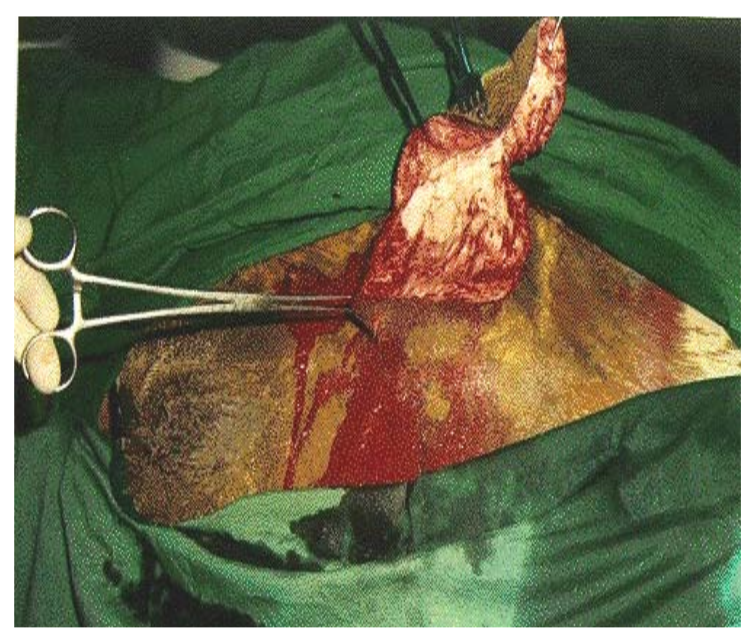

Fig. 5. Dissection of the skin from the inner sac.

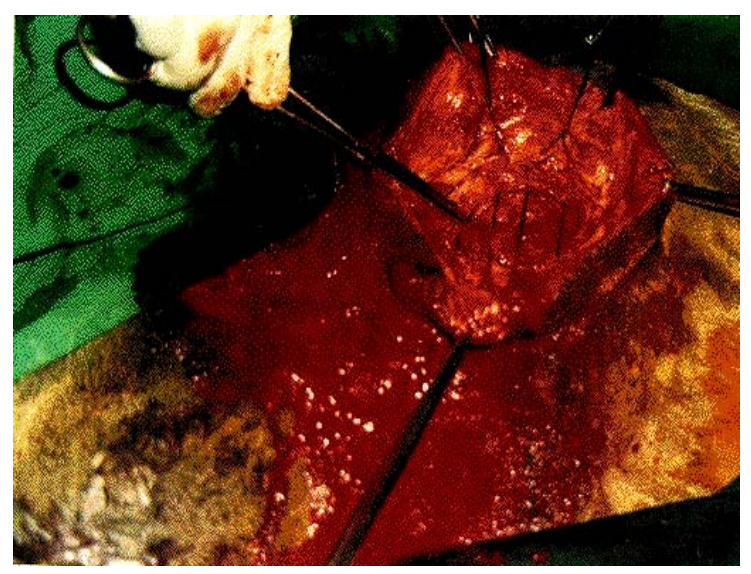

Fig. 6. Suturing the ring with interrupted MyoMattress sutures,

For inguinal hernia the animal was prepared as for abdominal hernia. The leg near the operated side was abducted. A 15$\mathrm{cm}$ long incision was started on the inguinal region and extended towards the base of the udder. The subcutaneous tissues were undermined to expose the external inguinal ring. The internal hernial sac was opened to identify the content (Fig.7). 


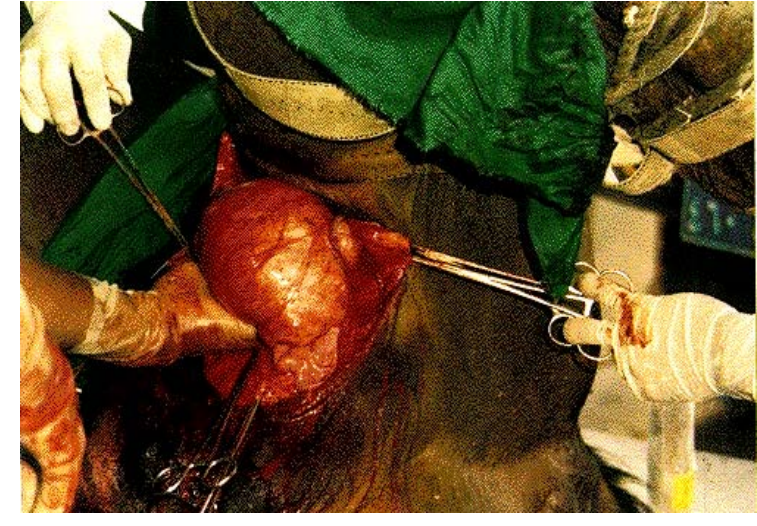

Fig. 7. Exposure of the inguinal region, hernial content intact

The hernial content was pulled by assistant through the rectum or through the vagina. The ring was then coaptated using double strand of Dexon II 6 metric. In one animal we were unable to bring the edges together and therefore a graft was obtained from the skin nearby after removing the hair and cutis. The inguinal fascia and skin were subsequently closed routinely (Fig.8).

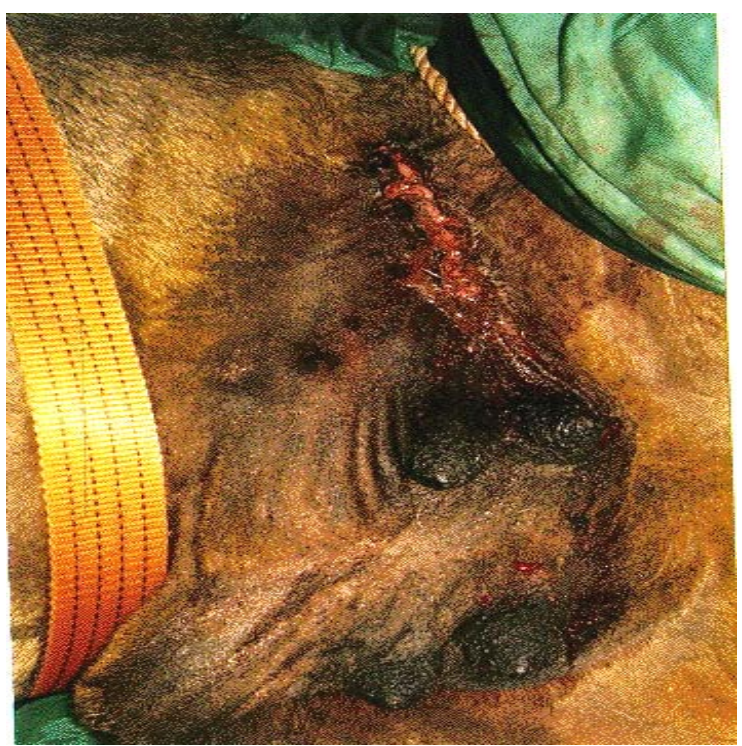

Fig. 8. Inguinal region after skin sutures

Local and parenteral dose of antibiotic was given to each animal. All animals made uneventful recovery.

\section{Discussion}

Although population-based incidence data on hernias in camels are lacking, the result of this study suggest that female are more prone to abdominal and inguinal hernias. Females were weaker than males and they were subjected to biting by excited males. Hernias may be congenital or acquired. Abdominal hernias represent the acquired variety caused by blunt injury at the aponeurosis of the tendons of external oblique and internal oblique muscles (Tirgari 1979). Abdominal hernia could also be incisional where it developed after cesarean operation. During healing of such wound, knot stability was weakened and the muscles were partially or completely disrupted while the skin remained intact. This was followed by various degrees of indurations at the operative site (Bolbol and Ramadan 1992).

Isolated report in the horse, dog and heifers suggested that inguinal hernias could be congenital or acquired (Snow, 1956; Moll and Angel, 1992; Marien et al 2001). The incidence of inguinal hernia was higher in bitches than in other animals and this was attributed to inherent widening of the internal inguinal ring and the presence of round ligament of the uterus (Jub et al. 1985).

In the present study, two immature camels had inguinal hernias, a finding that would suggest developmental natures of the condition. On the other hand, the other three animals developed the hernia insidiously, several months after parturition. This may suggest that such hernia could be traumatic in nature. It could have happened due to exertion during the last parturition or as a result of entrapment of the limb of the fetus. Several studies are needed to elucidate these fallacies. 
The presence of part of the liver inside the hernial sac would render the organ to become more vulnerable to rupture in case of accidental injury. The management of hernial defect is still a matter of controversy. Many surgeons still regard herniorrhaphy with or without dissecting the inner hernial sac, their choice (Ramadan, 1994). Other surgeons would encourage using commercial polyester fabric as a prosthetic mesh for reconstruction of major hernias to bridge the ring in areas with excessive tension (Shoukry et al, 1997). Inguinal hernia might confuse with chronic mastitis. However differentiation could be made by identification of the ring as well as exploratory puncture. Follow-up evaluation by verbal communication with some owners, several months postoperatively, revealed no problem in many of these cases.

\section{Acknowledgements}

We are grateful to our colleagues who referred cases for treatment.

\section{References}

Abdin-Bey, M.R and R. O. Ramadan, 2001. Retrospective study of hernias in goats. Sci. J. King Faisal Univ. 2: (In press).

Bolbol, A.E and R. O. Ramadan, 1992. Postcaesarian hernias in camels - A report of three cases. Assiut Vet. Med. J. 27:248251

Gahlot, T. K 2000. Surgery of the dromedary camel. In selected topics on camelis. 1st Edn. Sankhla Printers, Sugan Niwas, Chandan Sagar Well, Bikaner-334001, India P.426-427

Jub, K.V.F, P. C. Kennedy, and N. Palmer, 1985. Pathology of domestic animals. New York Academic Press. Inc. p. 65

Marien, T, van Hoeck, F. A. Adriaenssen and L. Segers 2001. Laparoscopic testis sparing herniorrhaphy: A new approach for congenital inguinal hernia repair in the foal. Equine Vet. Education. 69-72.

Moll, H.D and K. L. Angel 1992. Congenital parainguinal hernia in a heifer. J. Amer. Vet. Med. Assoc. 200:1527

Purohit, N.R, D. S. Chouhan and R. J. Choudhary 1989. Post cesarean ventral hernia in two camels. Brit. Vet. J. 145:294

Purohit R. K., D. S. Chouhan and N. R. Purohit 1982. Ventral hernia in camel (Camels dromedarius) and its treatment by herniorrhaphy. Indian J. Vet. Surg. 3:106-107.

Ramadan, R.O, R. A. Kock, and A. J. Higgins 1986. Observation on the diagnosis and treatment of surgical conditions in the camels. In: the camel in health and disease. Ed. Higgins, A. Baillier Tindal, London. P.132-133.

Ramadan, R.O 1994. Surgery and Radiology of the Dromedary Camel. 1st Edn. King Faisal University, P.O.Box 1757, Alhasa 31982, Saudi Arabia.

Sobiraj, A. 1994. Birth difficulties in sheep and goats, evaluation of patient outcome from seven laming periods in obstetrical clinic. DTW. Dtsch-TierarztWochenschr, 101-471-476.

Shoukry, M, M. El-Keley, M. Hamouda and S. Gadallah 1997. Commercial polyester fabric repair of abdominal hernias and defects. Vet. Rec. 140:606-607.

Snow R 1956. Inguinal metrocele (Gravid) in a bitch. J.Amer.Vet. Med Assoc. 359360.

Tirgari, M 1979. Ventral hernia in the sheep. Vet. Rec. 106:7-9 